\title{
Overview of the 4th CSRS Instructional Course Hands on Cadaver
}

\author{
- Alan Leonard \\ Senior International Product Manager, Cervical Products, DePuy Spine International
}

For many years, DePuy Spine has been in the forefront of designing, organising and delivering high quality surgeon education in various forms particularly instructional workshops at Spine Society Meetings as well as our own Cadaveric based Instructional Courses covering the length of the spine. So it was a great privilege for DePuy Spine to be one of the main sponsors of the last two CSRS organised Cervical Instructional Courses. This report offers a short overview of the most recent CSRS Cervical Instructional Course held in Barcelona, Spain on March 27th \& 28th 2009.

U nder the direction of the CSRS and with the co-operation of the team at the University of Barcelona : Prof. Andres Combalia, Associate Professor of the Department of Human Anatomy and Embryology, Prof. M Monzo, Director of Servicio Donación de Cuerpos y Salas de
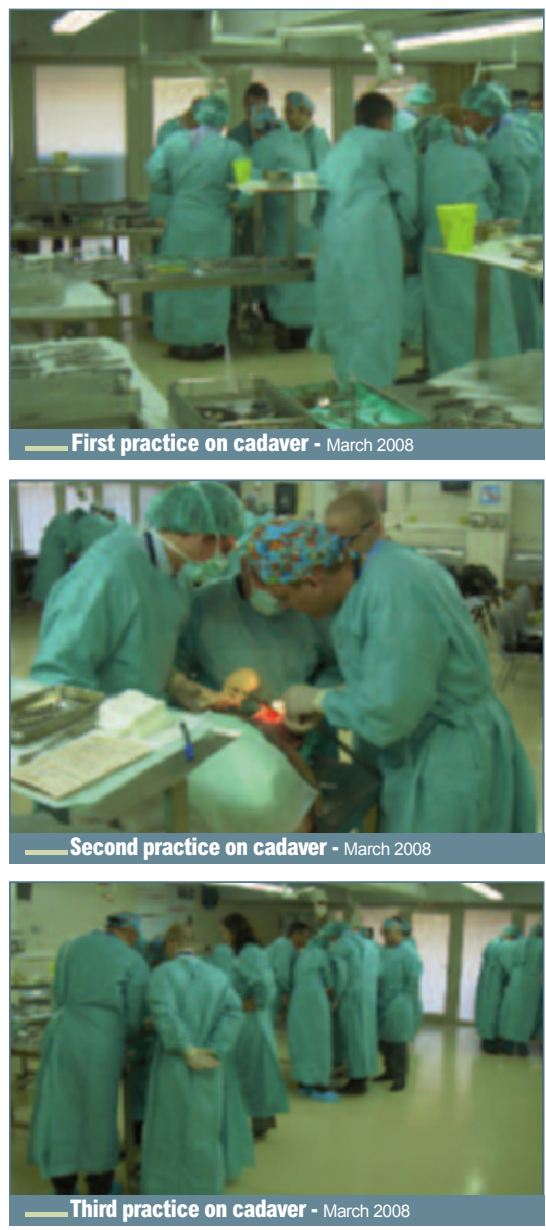

Disección and M.I. Miguel, Coordinator of the Dissection Room, a superb educational programme was developed.

After a welcoming introduction by both Drs. Andres Combalia and Jose Casamitjana and subsequent introduction of the other members of the CSRS Faculty of Claes Olerud, Robert Melcher, Ronald Bartels, Philippe Bancel, Jan Goffin, Carlos Villas, Andre Jackowski, the group of International surgeon delegates listened to the first session of didactic lectures. This section included important and highly relevant posterior cervical spine topics such as: Anatomy \& Surgical Remarks of the Cranio-Cervical Junction and Occipito-Cervical Fixation by Prof. Claes Olerud, Atlanto-Axial Instability and C1-C2 Fixation by Dr. Med. Robert Melcher.

After the lecture session, the groups went to the dissection tables for the first dissection practice on cadaver specimens for practical teaching on Posterior Approach, Occiput and C1-C2 Fixation.

For the second didactic lecture session after a short coffee break, Dr Philippe Bancel presented on Anatomy and Biomechanics of the Cervical Spine and the technique for Lateral Mass screw fixation. Dr Ronald Bartels followed on with an overview of the fascinating minimal invasive technique of Skip Laminectomy. Again, the groups went directly to the dissection tables for further dissection practice on these techniques.

After lunch, Dr Bancel lectured on the Cervico'Thoracic Junction followed by the last dissection practice of the day. Finally, the day was rounded off with interesting case presentation and discussions.

Day two of the course focussed on Anterior Approaches to the Cervical Spine. Following a similar format of the first Posterior Cervical day, lectures included Trans Oral Approach by Claes Olerud, Anterior Approach Sub-axial Spine - Fusion or Disc Replacement? - by Jan Goffin, Intersomatic Devices \& Multilevel Corpectomy - Bengt Lind and finally

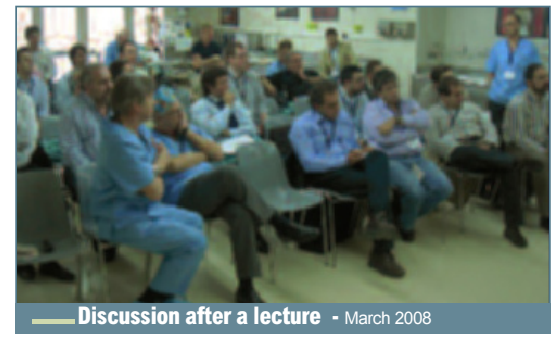

Lateral Approach and trans Uncodiscal Foraminotomy - Andre Jackowski. Each didactic lecture was again followed by practical 'hands on' cadaveric dissection sessions where instruction and advice was offered by the faculty relative to the lecture sessions.

The course was a great success and was rated very highly by the delegate group. It was the pleasure of DePuy Spine to have present at the course, our comprehensive dissection instrument sets as well as our Cervical Implant Products for the six dissection tables during the cadaveric practice sessions, as well as to be a valuable partner to the Cervical Spine Research Society as they endeavour to provide excellent educational courses such as this 